\title{
Morphology and Morphometric Study of Superior Orbital Fissure in Dried Human Skulls
}

\section{ABSTRACT}

Introduction: Superior Orbital Fissure (SOF) is the major gateway into the orbit from the cranial cavity. Important nerves and vessels pass through it. Variation in the shape and its measurements greatly influence the course and distribution of these structures.

Aim: To study the dried human skulls and observe the shape of the SOF and to measure the superomedial and superolateral edges along with the distance between them.

Materials and Methods: This study was cross-sectional, conducted over a period of one year starting from July 2019 to June 2020 at Osmania Medical College, Hyderabad, on 51 dried human skulls which were thoroughly examined and their shape was noted and photographed. The measurements were taken using Vernier calliper and statistically analysed using Microsoft Excel with frequency (n) and percentage (\%) analysis.

Results: The predominant shape was type VI on both right and left sides. The mean superomedial edge height was $10.07 \pm 0.85 \mathrm{~mm}$ on right and $9.72 \pm 0.71 \mathrm{~mm}$ on left side. The mean superolateral edge height was $3.76 \pm 0.75 \mathrm{~mm}$ on right and $3.65 \pm 0.87 \mathrm{~mm}$ on left side. The mean distance between superomedial to superolateral edges was $19.52 \pm 0.65 \mathrm{~mm}$ on right side and $19.01 \pm 0.65 \mathrm{~mm}$ on left side.

Conclusion: Nine different shapes of superior orbital fissure were found in the study and type VI was the most frequently observed shape. The study did not find any difference between the widths of the right and the left SOF in dried human skulls.

Keywords: Cranium, Nerves, Orbit, Superomedial, Superolateral, Vernier calliper

\section{INTRODUCTION}

The SOF is a major gateway into the orbit from the cranial cavity. It is a gap between lesser and greater wings of sphenoid bone [1]. It is a complex region in the middle cranial fossa, functionally very important region in respect of the structures which it transmits III, IV, $\mathrm{VI}$ cranial nerves and vessels. Knowledge of detailed micro anatomy of superior orbital fissure is very important in making better clinical diagnosis and minimising the complications [2].

Pathological conditions of cavernous sinus like traumatic carotid cavernous sinus fistula can cause SOF syndrome due to the involvement of nerves in relation to cavernous sinus and orbit. Inflammation and infections of Central Nervous System (CNS), meninges, cavernous sinus, retro-bulbar space caused by syphilis, tuberculosis also causes SOF syndrome [3]. Compression of SOF contents in unnatural narrowing of the SOF is seen in aneurysms of internal carotid artery [4].

In view of all the possible clinical conditions of SOF structures, microanatomy of SOF guides, ophthalmologists and neurosurgeons during surgical interventions and help in the development of new strategies in studying the microanatomy $[2,5]$.

\section{MATERIALS AND METHODS}

The present cross-sectional study was conducted over a period of one year from July 2019 to June 2020 at Osmania Medical College and Bhaskar Medical College, Hyderabad, Telangana, India. The study was done under the guidance of Head of the Department in dried cadaveric bones.

Inclusion criteria: The dry human skulls with full superior orbital fissure were included in the study.

Exclusion criteria: Broken skulls and cadavers were excluded.

Fifty-one dried human skulls were thoroughly examined and their shape noted and photographed as described by Sharma PK et al. [6]. Using the Vernier calliper, height of the supero-medial (A) and superolateral $(B)$ edges along with the distance between them (distance between $A$ and $B$ ) were noted on both the sides. The mean value of these measurements was calculated [Table/Fig-1-3].

\section{STATISTICAL ANALYSIS}

The descriptive statistical analysis was done using Microsoft Excel and frequency (n) and percentages (\%) were calculated from the collected data.

\section{RESULTS}

Present study found the most common shape of SOF was Type VI on both right and left sides. The second common type was type

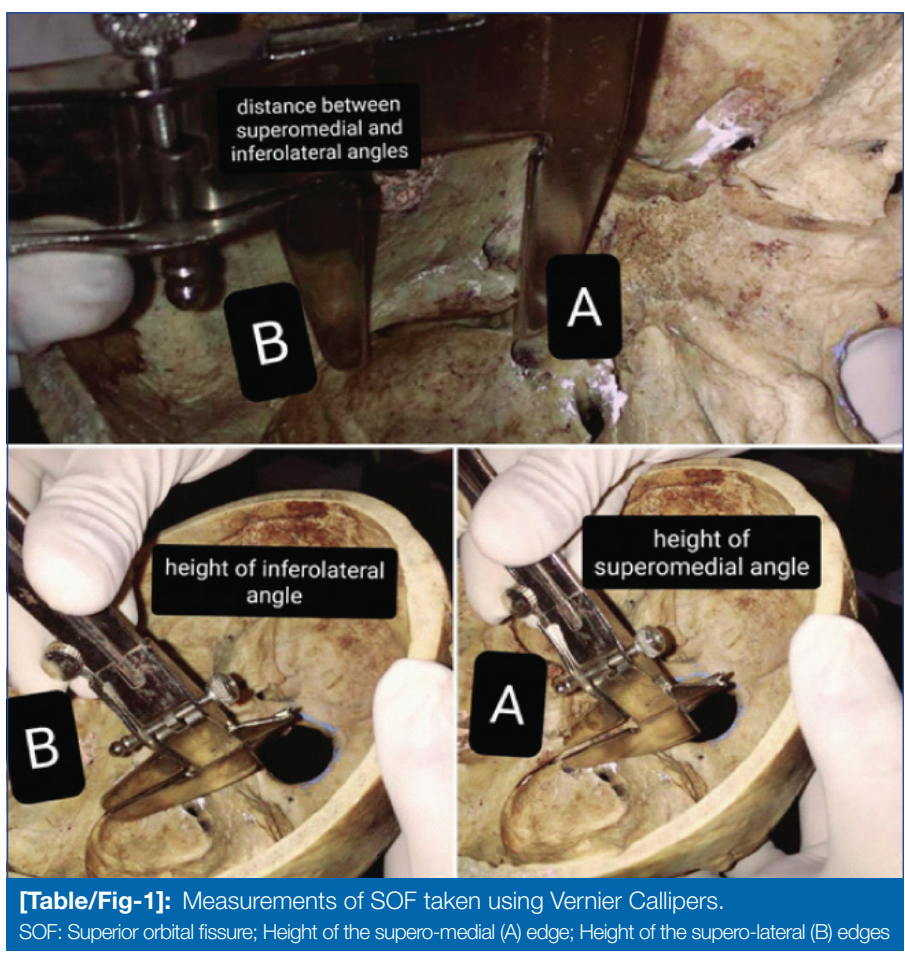


VIII in Right SOF and Type III in Left SOF [Table/Fig-3-6]. One skull showed narrowed SOF on right side [Table/Fig-7].

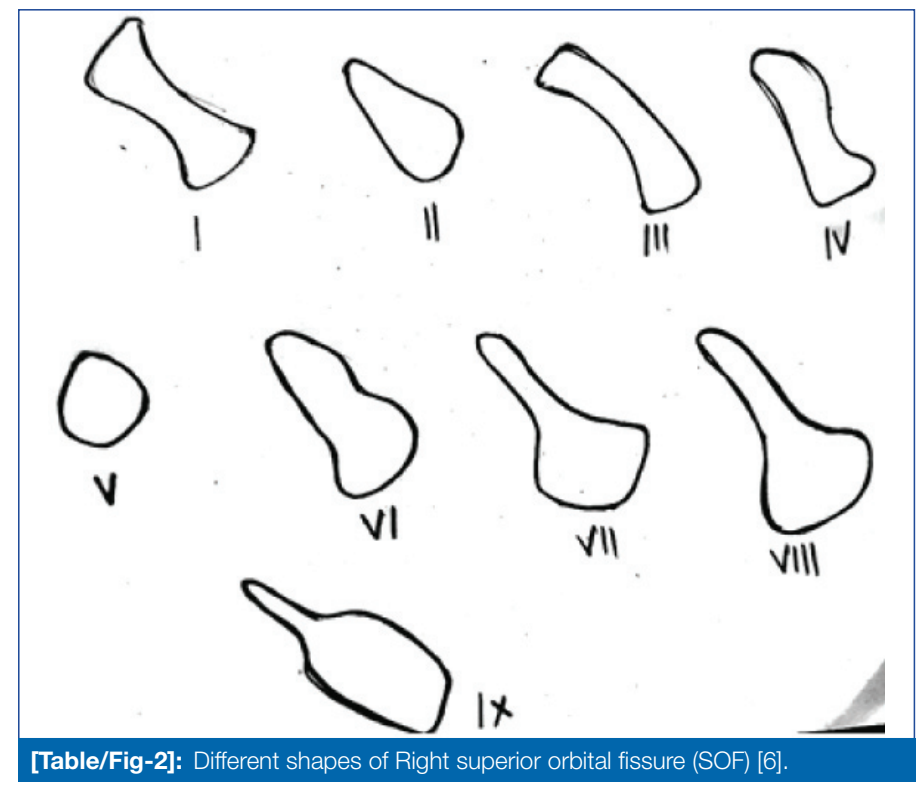

\begin{tabular}{|l|c|c|}
\hline Type of shape & Right N (\%) & Left N (\%) \\
\hline Type I & 0 & 0 \\
\hline Type II & $4(8 \%)$ & $4(8 \%)$ \\
\hline Type III & $8(15 \%)$ & $9(17 \%)$ \\
\hline Type IV & $1(2 \%)$ & $1(2 \%)$ \\
\hline Type V & $4(8 \%)$ & $2(4 \%)$ \\
\hline Type VI & $17(33 \%)$ & $23(45 \%)$ \\
\hline Type VII & $6(12 \%)$ & $4(8 \%)$ \\
\hline Type VIII & $8(16 \%)$ & $6(12 \%)$ \\
\hline Type IX & $3(6 \%)$ & $2(4 \%)$ \\
\hline [Table/Fig-3]: Shapes of Superior Orbital Fissure (SOF).
\end{tabular}

\begin{tabular}{|c|c|c|}
\hline Measurements of SOF & Right side & Left side \\
\hline Mean superomedial edge height & $10.07 \pm 0.85 \mathrm{~mm}$ & $9.72 \pm 0.71 \mathrm{~mm}$ \\
\hline Mean supero-lateral edge height & $3.76 \pm 0.75 \mathrm{~mm}$ & $3.65 \pm 0.87 \mathrm{~mm}$ \\
\hline $\begin{array}{l}\text { Mean distance between the superomedial } \\
\text { and superolateral angles }\end{array}$ & $19.52 \pm 0.65 \mathrm{~mm}$ & $19.01 \pm 0.65 \mathrm{~mm}$ \\
\hline
\end{tabular}

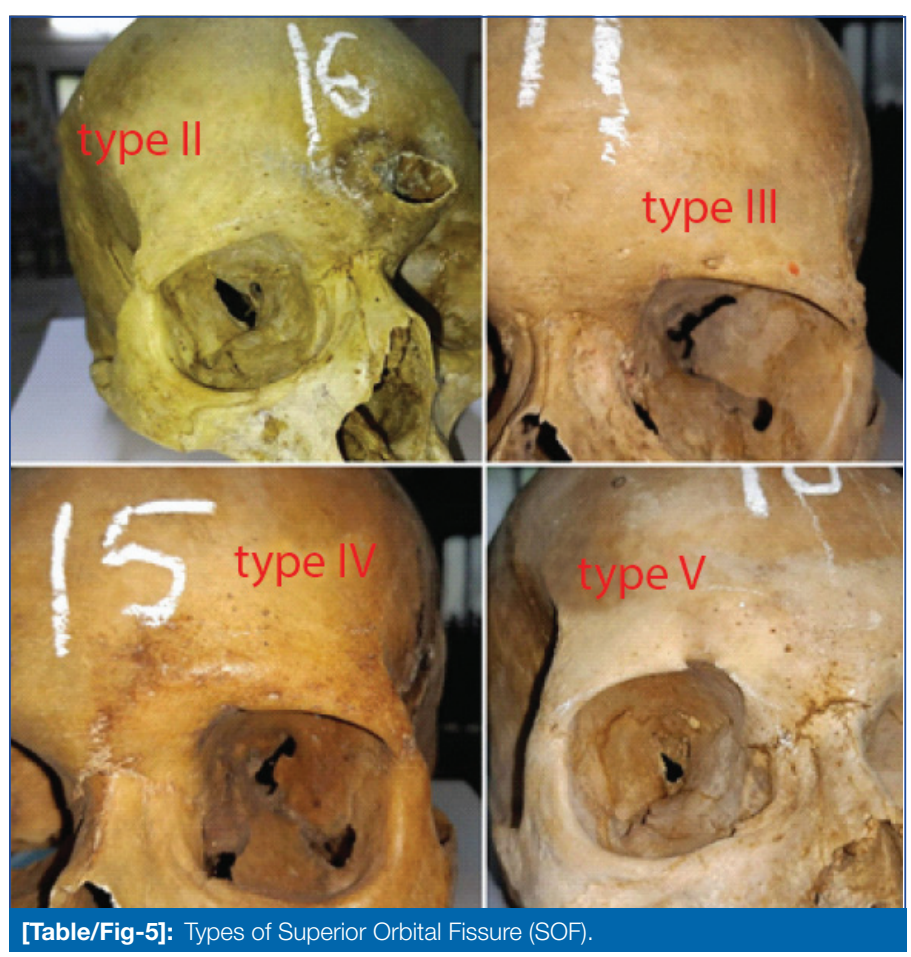

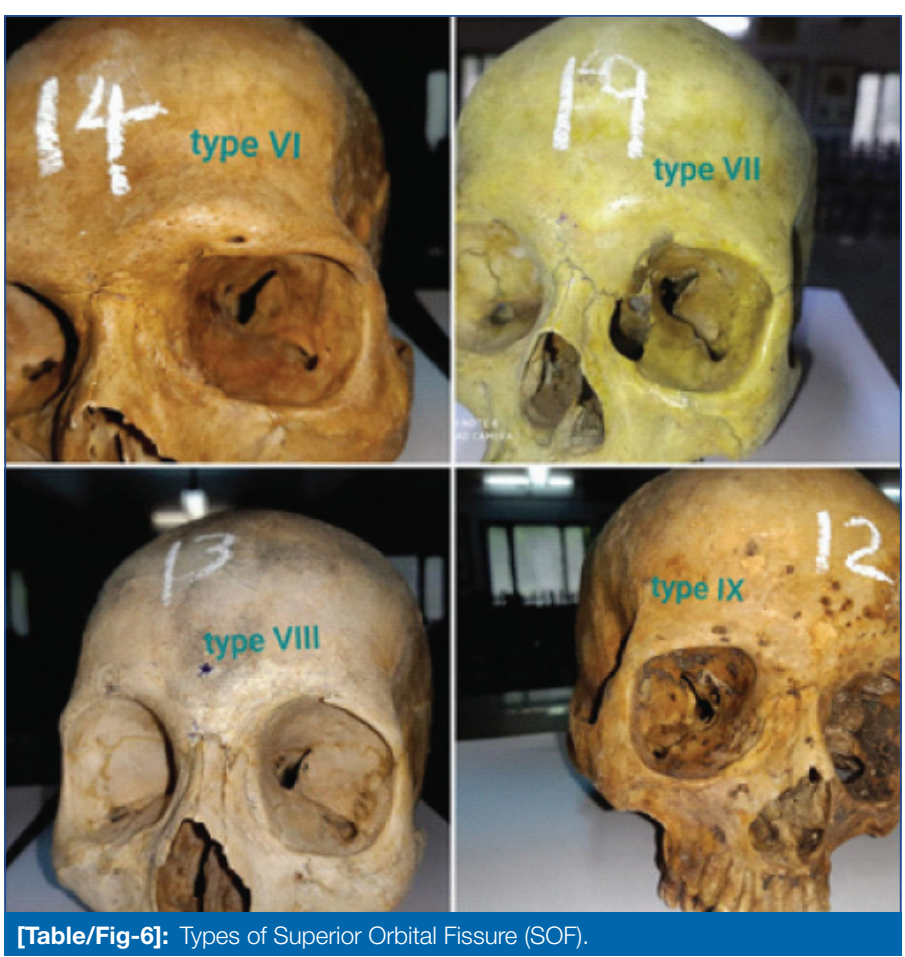

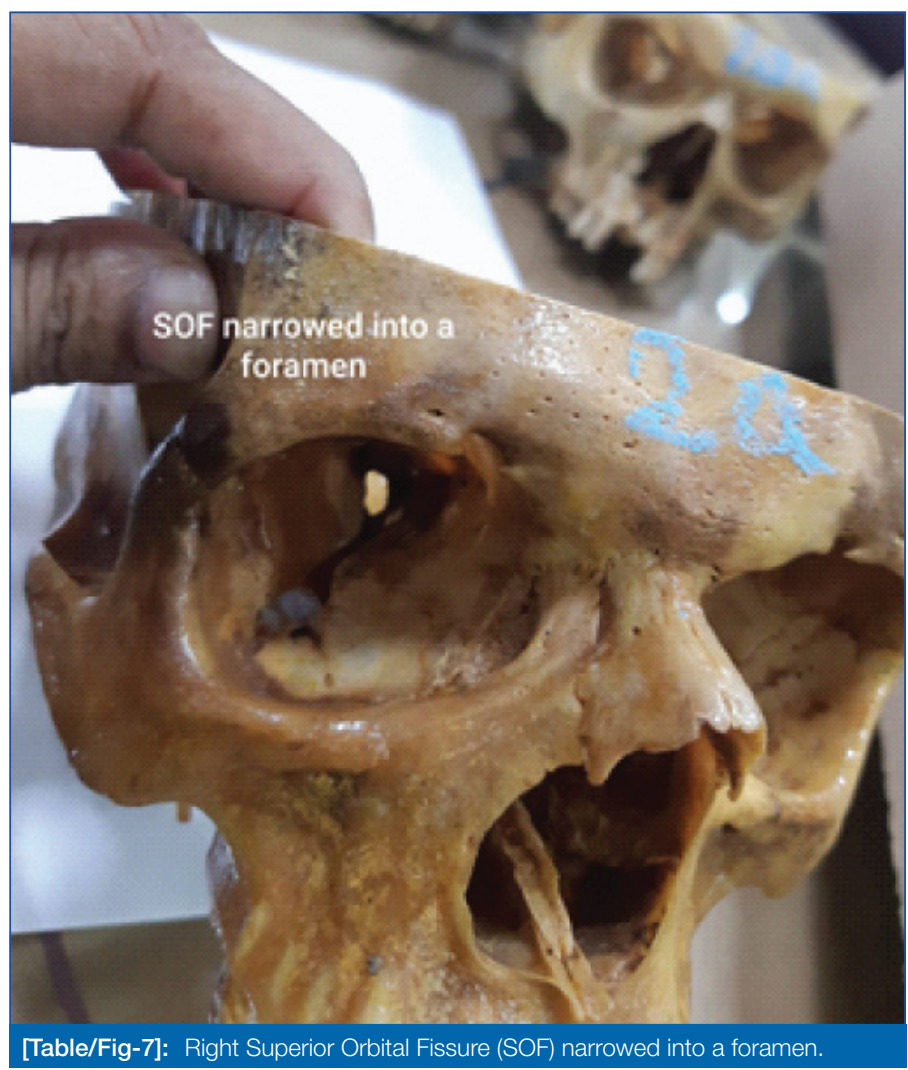

The mean superomedial edge height was $10.07 \pm 0.85 \mathrm{~mm}$ on right and $9.72 \pm 0.71 \mathrm{~mm}$ on left side. The mean superolateral edge height was $3.76 \pm 0.75 \mathrm{~mm}$ on right and $3.65 \pm 0.87 \mathrm{~mm}$ on left side. The mean distance between superomedial to superolateral edges was $19.52 \pm 0.65 \mathrm{~mm}$ on right side and $19.01 \pm 0.65 \mathrm{~mm}$ on left side [Table/Fig-4].

\section{DISCUSSION}

The SOF is wider medially with long axis sloping infero-medially and forwards [1]. Apex of the orbit is at the medial and lower end of the SOF where it is widest, extends obliquely in lateral direction and forwards between the roof and lateral wall of the orbit [7]. It is observed in different shapes varying from an oblique cleft, roughly triangular to club shaped or slit like opening in the middle cranial 
fossa $[2,6]$. Different shapes of SOF as described by Sharma PK et al., are shown [Table/Fig-6,7] [6].

Position of soft tissue structures in SOF depends on its morphological type, whether clear narrowing of SOF is present or lack of such narrowing [8]. Based on its shape, nine types of SOF were observed, which also gives the diversity of positioning of soft tissue structures within these nine types. These variant types of SOF help to understand the underlying cause for the clinical conditions and guide in surgical interventions in variant cases. Any change in the shape of SOF due to local causes leads to compression of structures within it and in turn results in neurological deficits and vascular involvement and the majority noticed that SOF was Type VI among nine different shapes according to PK Sharma classification [2].

Reymond $J$ et al., distinguished nine morphological types of the SOF. Among those were two main categories: type "a" characterised by a clear narrowing within the fissure and type "b" which lacked such narrowing. The type "a" and "b" fissures were also different in length whereby type "b" fissure was significantly shorter [9]. Present study followed the classification described by Sharma PK et al., [6]. One skull showed a narrowed SOF on the right side [Table/Fig-7] which corroborates to the type b SOF as described by Reymond $J$ et al., Govsa F et al., found that, on right side, distance was $17.3 \pm 3.4 \mathrm{~mm}$ from superomedial to the superolateral edge and on left side, it was $16.9 \pm 2.9 \mathrm{~mm}$. Measurements were $20.8 \pm 3.9 \mathrm{~mm}$, the superolateral to the inferior edge on right side and left side it was $20.1 \pm 3.8 \mathrm{~mm}$. It was $9.5 \pm 2.2 \mathrm{~mm}$ on the right and $9 \pm 2.4 \mathrm{~mm}$ on the left side when the distance measured from the superomedial to the inferior edge of fissure [2,9]. The results of the present study does not correlate with those of Govsa F et al., because the latter was conducted on cadavers in relation to soft tissue structures around the SOF but the present study was conducted on dried human skulls.

Desai SD and Sreepadma S found that the SOF measurements were $0.9 \mathrm{~cm}$ vertically and $0.6 \mathrm{~cm}$ transversely on right side, and on the left side it was $0.9 \mathrm{~cm}$ vertically and $1.4 \mathrm{~cm}$ transversely with the fissure showing normal shape [10]. The study by Shukla A et al., on SOF reported that the mean length of right SOF was $1.39 \pm 0.21 \mathrm{~cm}$ while that of $1.4 \pm 0.24 \mathrm{~cm}$ on left side [11].

According to the results by Dande $\mathrm{K}$ et al., the occurrence of triangular fissure in right side SOF was $19.35 \%$ (24), classical fissure $18.54 \%$ (23), oval $7.25 \%$ (9) and irregular $4.83 \%$ (6) and on the left SOF, occurrence of triangular fissure was $10.48 \%$ (13), classical fissure $27.41 \%$ (34), oval $7.25 \%$ (9) and irregular $4.83 \%$ (6). The mean length of the fissure SOF was $1.683 \mathrm{~cm}$ on right and $1.661 \mathrm{~cm}$ on left side. On right side the mean width of the fissure of SOF was $0.824 \mathrm{~cm}$ and on left side it SOF was $0.906 \mathrm{~cm}$ [12].

The study by Park $Y$ and Kim $Y$ reported the following- mean SOF width was $3.79 \pm 0.93 \mathrm{~mm}$, and the values for the left SOF were $3.79 \pm 0.96 \mathrm{~mm}$ and $3.783 \pm 0.92 \mathrm{~mm}$ for the right SOF, the widths of the SOFs were $3.62 \pm 1.35 \mathrm{~mm}$ on the left side, $3.69 \pm 1.18 \mathrm{~mm}$ on the right side, and $3.65 \pm 1.26 \mathrm{~mm}$ across both sides. In the females [13], present study was based on dried human skulls so the results are dissimilar because Park $Y$ and Kim $Y$ focused on measurement of SOF widths on CT scans at optic canal level [13].

Rasheed $A$ et al., found that the right supraorbital foramen of all skulls showed mean transverse diameter $2.420+.451 \mathrm{~mm}$ while, left supraorbital foramen showed 2.139+.391 mm. Right side supraorbital foramen of all skulls showed mean vertical diameter 3.649+.687 $\mathrm{mm}$ while left sided foramen showed
$3.489+.651 \mathrm{~mm}$. Mean transverse diameter of right infraorbital foramen, was $2.858+.633 \mathrm{~mm}$ and left was $3.112+.823 \mathrm{~mm}$. mean vertical diameter was $4.199+.732 \mathrm{~mm}$ on right side and it was $4.229+.887 \mathrm{~mm}$ on left side [14]. Present study does not correlate with the study by Kimura K; possible reason of which may be the racial variation [15]. The position and location of SOF significantly differ in various races and between gender [16]. SOF measurements may be different between geographic zones and inhabitants of respective environments [17].

Measurements of SOF is clinically significant as narrowing of SOF less than $1.6 \mathrm{~mm}$ is a risk factor for SOF syndrome. Congenital narrowing is also a cause of SOF syndrome [3]. The present study showed one skull with narrow SOF on right side [Table/Fig-7]. In cranio-maxillo-facial trauma, structures which pass through SOF may get involved and damaged, which can give rise to conditions like Rochen-Duvigneaud syndrome [10]. The features are ophthalmoplegia, ptosis, proptosis, dilated and fixed pupils and loss of sensation of upper eyelid and forehead [3].

\section{Limitation(s)}

The study was conducted on dried human skulls, so the values show variations when compared to the studies done on live patients using computerised tomography scans.

\section{CONCLUSION(S)}

Nine different shapes of superior orbital fissure were found in present study and type VI was the more frequently observed shape on both sides. Present study found the most common shape of SOF was Type VI on both right and left sides. The second common type was type VIII in Right SOF and Type III in Left SOF. One skull showed narrowed SOF on right side. The mean width of the SOF in dried human skulls showed no difference between right and the left SOF. However, more future Computed Tomography scans based studies are recommended to further correlate the findings of this cadaveric study.

\section{REFERENCES}

[1] Standring S, Borley N, Henry G. The anatomical basis of clinical practice. Gray's Anatomy. Orbit. 41 $1^{\text {st }}$ ed. 2020; 425.

[2] Govsa F, Kayalioglu G, Erturk M, Ozgur T. The superior orbital fissure and its contents. Surgical and Radiologic Anatomy. 1999;21(3):181-85.

[3] Chen CT, Chen YR. Traumatic superior orbital fissure syndrome: Current management. Craniomaxillofacial Trauma \& Reconstruction. 2010;3(1):09-16.

[4] Ebenezer V. Superior orbital fissure syndrome: A review of literature. Indian Journal of Public Health Research \& Development. 2019;10(12):1061-63.

[5] Rohrich RJ, Hackney FL, Parikh RS. Superior orbital fissure syndrome: current management concepts. The Journal of Cranio-Maxillofacial Trauma. 1995; 1(2):44-48

[6] Sharma PK, Malhotra VK, Tewari SP. Variations in the shape of the superior orbital fissure. Anatomischer Anzeiger. 1988;165(1):55-56.

[7] Dixon AF. Dixon's manual of human osteology. Oxford University Press; 1937.

[8] Faruqi NA. Hand book of Osteology, $1^{\text {st }}$ edition. 2007;248.

[9] Reymond J, Kwiatkowski J, Wysocki J. Clinical anatomy of the superior orbital fissure and the orbital apex. Journal of Cranio-Maxillofacial Surgery. 2008;36(6):346-53.

[10] Desai SD, Sreepadma S. Partial closure of right superior orbital fissure with narrow optic foramen. IJAV. 2010;3:188-90. https://www.pulsus.com/scholarlyarticles/partial-closure-of-right-superior-orbital-fissure-with-narrow-opticforamenin.html.

[11] Shukla A, Bokariya P, Kothari R, Singh S. Measurement of orbital dimensions (orbital height, breadth and length of superior orbital fissure) using dry skull's. The Official Scientific Journal of Delhi Ophthalmological Society. 2020;31(1):41-44

[12] Dande K, Archana R, Verma RK, Sharma PK. Morphological and morphometric variation of superior orbital fissure. Journal of the Anatomical Society of India. 2017;66:S3. Doi: 10.1016/j.jasi.2017.08.014

[13] Park Y, Kim Y. A Statistical analysis of superior orbital fissure width in korean adults using computed tomography scans. Archives of Craniofacial Surgery. 2017;18(2):89-91.

[14] Rasheed A, Hina M, Kuraishi RT. Length of orbital margins of dry skulls in a local Pakistani population. Anatomy Journal of Africa. 2019;8(1):1470-73.

[15] Kimura K. Foramina and notches on the supraorbital margin in some racial groups. Kaibogaku Zasshi. 1977;52(3):203-09. 
[16] Cutright B, Quillopa N, Schubert W. An anthropometric analysis of the key foramina for maxillofacial surgery. Journal of Oral and Maxillofacial Surgery. 2003:61(3):354-57.
[17] Ari I, Mustafa I, ZubeydeBasar K, Ayberk Kurt M. The localization and anthropometry of mental foramen on late Byzantine mandibles. Collegium Antropologicum. 2005;29(1):233-36.

\section{PARTICULARS OF CONTRIBUTORS:}

1. Assistant Professor, Department of Anatomy, Osmania Medical College, Hyderabad, Telangana, India.

2. Assistant Professor, Department of Anatomy, Gandhi Medical College, Hyderabad, Telangana, India.

3. Professor and Head, Department of Anatomy, Government Medical College, Siddipet, Telangana, India.

\section{NAME, ADDRESS, E-MAIL ID OF THE CORRESPONDING AUTHOR:}

Parimala Sirikonda,

301/B, Rockcliff Thirtha Apartment, Bandlaguda Jagir, Gandipet Mandal,

Rangareddy District, Hyderabad-500086, Telangana, India.

E-mail: pari.siri@gmail.com

\section{AUTHOR DECLARATION:}

- Financial or Other Competing Interests: None

- Was Ethics Committee Approval obtained for this study? NA

- Was informed consent obtained from the subjects involved in the study? NA

- For any images presented appropriate consent has been obtained from the subjects. NA
PLAGIARISM CHECKING METHODS: [Jain Het al.]

- Plagiarism X-checker: Oct 21, 2020

- Manual Googling: Sep 25, 2021

- iThenticate Software: Oct 16, 2021 (10\%)
ETYMOLOGY: Author Origin Date of Peer Review: Dec 24, 2020 Date of Acceptance: Oct 05, 2021 Date of Publishing: Jan 01, 2022 